\title{
Science Academies' Refresher Course on Theoretical Structural Geology, Crystallography, Mineralogy, Thermodynamics, Experimental Petrology and Theoretical Geophysics
}

\author{
at \\ Indian Academy of Sciences Facility, Jalahalli, Bangalore 20 November-04 December 2017 \\ Sponsored by Indian Academy of Sciences, Bengaluru \\ Indian National Science Academy, New Delhi \\ The National Academy of Sciences, India, Allahabad
}

\begin{abstract}
A course on Theoretical Structural Geology, Crystallography, Mineralogy, Thermodynamics, Experimental Petrology and Theoretical Geophysics will be conducted in the Jallahalli Campus under the aegis of Indian Academy of Sciences during 20th November to 4th December, 2017. University lecturers, Research Scholars, MSc/M.Tech students in the field of Earth Science with good scholastic record may apply, a knowledge of undergraduate mathematics is mandatory. TA (third class AC) as per rule of the academy will be permitted. The number of applicants to be selected is 25 . A list of five participants would be kept on reserve in case some candidates cannot make it.
\end{abstract}

Teachers who wish to participate in the Refresher Course may apply through proper channel with the following details: name, date of birth, gender, e-mail, official and residential addresses, telephone numbers, academic qualifications, courses taught, affiliation, positions held and tenure. It is also essential to submit a brief statement (between 250 and 500 words) as to why they think the Course will help to improve their classroom teaching of Geology/Earth Science. Applications should be submitted ONLINE by clicking the following link:

http://web-japps.ias.ac .in: 8080/Refreshcourse/RCCR . jsp

A print copy of the application must also be sent by speed post forwarded by the head of the institution. Outstation candidates will be provided local hospitality and round trip bus/train (three-tier AC) fare by the shortest route. Course Director: Professor Alok K Gupta, University of Allahabad, Allahabad, U.P. 211002

Course Coordinator: Dr T D Mahabaleswara, Coordinator (RC\&LW), Science Education Panel, Indian Academy of Sciences, C. V. Raman Avenue, Sadashivanagar P.O., Bangalore 560080 (Email: sep@ias.ac.in).

It should reach the Course Coordinator before 15 September 2017.

The last day of receiving application would be 7th October. 2017. 